\title{
Análise das capas de livros de Vicente Di Grado: década de 1960
}

\author{
Analysis of Vicente Di Grado's book covers: 1960 decade \\ Márcio Duarte, Mônica Moura
}

design brasileiro, Vicente Di Grado, capas de livros

\begin{abstract}
Esse artigo pretende contribuir para o resgate da história do design brasileiro a partir do estudo de uma seleção de capas produzidas na década de 1960 por Vicente Di Grado (1922 - 2004), principal capista e ilustrador da Editora Clube do Livro. As capas selecionadas e analisadas por meio das questões formais e da sintaxe visual e contextual em suas relações com o design da informação.
\end{abstract}

Brazilian design, Vicente Di Grado, book covers

This article intends to contribute to the Brazilian design history through a study of a selection of book covers produced in 1960 decade by Vicente Di Grado (1922 - 2004), who was the main cover artist and illustrator of a publishing house named Clube do Livro. The covers were analysed considering their visual and contextual syntax and in their relations with information design.

\section{Introdução}

A história do design brasileiro ainda possui lacunas que apontam problemas de memória cultural e indicam a necessidade de um resgate mais amplo a seu respeito. Pouco se pesquisou sobre os primeiros artistas a trabalhar com segmentos específicos, como o design editorial, principalmente no período de crescente fervor editorial que foram os anos de 1950 e 1960 que apresentaram mudanças no padrão gráfico existente até então e ocorreu a criação de formatos diferenciados de expressão visual nos produtos de design editorial.

Esse texto busca trazer uma contribuição para o resgate histórico do design brasileiro no campo editorial, especificamente, no resgate e estudo de capas, a partir dos levantamentos e análises de cinco capas aqui apresentadas que foram desenvolvidas por Vicente Di Grado nos anos de 1960 para a Editora Clube do Livro.

\section{0 design editorial brasileiro}

Os autores estudados para essa pesquisa Hallewell (1985), FerlautoE (2002), Cardoso (2005), Moraes (2006), Melo (2007), apontam quatro aspectos fundamentais a respeito do design editorial brasileiro:

1. A expansão das editoras brasileiras, a partir de 1920, como resultado da renovação tecnológica e comercial das indústrias gráficas nacionais, do crescimento dos núcleos urbanos e da ampliação do mercado literário;

2. O design editorial é basilar na tradição e história do design brasileiro, mas a grande parte dos estudos desenvolvidos a esse respeito indica como protagonistas os autores, editores e editoras, e cabe para os profissionais que criaram e projetaram os livros, apenas o papel de figurantes. Portanto, é essencial retomar a história a partir de outros estudos e pesquisas para disseminar a importante atuação dos designers editoriais ou designers de capas esquecidos;

3. A importância das capas como elemento primeiro de informação a respeito do livro que cumpre um papel ímpar nas dimensões comunicacionais, informacionais e de visualidade 
na relação dos livros com os leitores a partir da integração entre a ilustração e a tipografia relacionando questões sintáticas e semânticas do produto editorial;

4. A produção de capas ilustradas no cenário brasileiro, a partir dos anos de 1920 , é singular e apresenta grande riqueza nas produções, porém ainda pouco exploradas em estudos e pesquisas.

\section{Editora Clube do Livro e Vicente Di Grado}

Os últimos vinte anos trouxeram uma grande disseminação do design brasileiro devido a vários fatores que resultaram na valorização do campo do design. Estudos, pesquisas e produções acadêmicas desenvolveram-se e apresentaram fatos marcantes até então inexplorados na cultura brasileira, mas também indicaram uma série de ausências e caminhos para novas pesquisas. Especialmente sobre profissionais que atuaram no design brasileiro e suas produções, que apesar de significativas, estão restritas a acervos específicos e desconhecidos do público.

Um desses profissionais foi o paulista Vicente Di Grado que teve atuação significativa na área editorial, com vasta obra produzida para a Editora Clube do Livro onde trabalhou como capista e ilustrador. O Clube do Livro foi fundado em 1943 e teve atuação em todo o território nacional. A proposta dessa editora era a de popularizar a leitura oferecendo livros baratos com obras de importante valor cultural para formar bibliotecas nos lares brasileiros. O sistema de trabalho dessa editora dava-se por meio de assinantes que contribuíam com uma parcela mensal, em troca recebiam livros de literatura nacional ou internacional. Em 1969 essa editora contabilizava cerca de 50 mil associados. Sua produção era em escala industrial e a cada mês um novo título era lançado. Para isso, contava com capistas e ilustradores profissionais para atender a toda essa demanda. Um dos capistas e ilustradores com maior atuação na Editora Clube do Livro foi Vicente Di Grado, especialmente durante a década de 1960.

Vicente Di Grado (1922 - 2004), artista plástico formado pela então Faculdade de Belas Artes, foi o principal capista e ilustrador da Editora Clube do Livro, tendo desenvolvido seu trabalho para essa editora entre as décadas de 1950 e 1970, .Publicou cerca de 250 capas as quais retratam o modo expressivo como conduzia seus projetos e suas criações.

A capa dos livros era o elemento de maior destaque e singularidade, sendo produzida especificamente para cada título editado pelo Clube do Livro. Já a parte interna do livro mantinha a mesma estrutura de diagramação, visando facilitar e agilizar o processo produtivo em alta escala.

Essa pesquisa examina como se deu a relação de Di Grado com a área do design editorial a partir da análise de um período de sua produção - década de 1960 - e, verificar as características e elementos de sua produção, examinar como se deram as relações com o design da informação a partir dos aspectos sintáticos visuais existentes em seu trabalho.

\section{A capa como veículo do design, da informação e da comunicação}

O conjunto de livros desenvolvido por Vicente Di Grado para a Editora Clube do Livro, conta com cerca de 250 capas produzidas entre o início da década de 1950 até meados da década de 1970 quando ocorreu uma ruptura no perfil editorial do Clube do Livro, ao ser adquirido por um grupo editorial maior, em 1973 (HALLEWELL, 1985, p 411), iniciando o declínio de suas atividades.

Durante a década de 60, Cardoso (2009), fala sobre as capas de livros que, ao ganharem dimensões próprias, são valorizadas, graças a experiências de artistas gráficos, como Eugênio Hirsch, para a Editora Civilização Brasileira, que apresenta soluções diferenciadas para a comunicação dos livros, atraindo os leitores/consumidores pelo apelo visual que apresentam.

Assim, as capas adquirem aspectos informacionais que, segundo os princípios do Design da Informação e conforme Dürsteler (2000), definem algumas condições para se obter um processo de entendimento de uma mensagem, ou seja, qual é? Para quem? E qual propósito? - seu conteúdo, linguagem e forma - independente do meio escolhido, satisfazendo requisitos estéticos, econômicos, ergonômicos, além dos requisitos de conteúdo (PETTERSSON, 2002).

Uma capa comunica o conteúdo de uma obra, de um título, e faz este papel tornando o livro um objeto advindo de um processo de design. Löback (2001), denomina essa questão como 
comunicação estética onde o papel do designer é de emissor de uma mensagem, a qual será entendida ou recebida pelo receptor - o leitor, conforme esquema a seguir (figura 1):

Figura 1: Processo de comunicação estética do livro. Adaptado de Löback, 2001, p. 157.

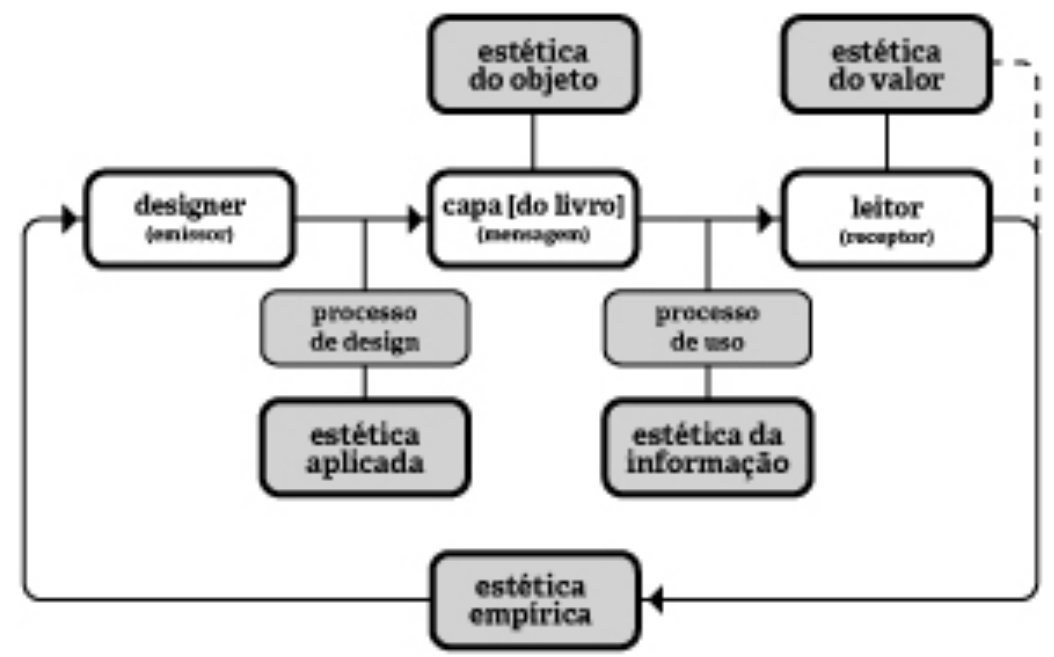

Assim, quando o designer ou artista gráfico desenvolve a capa para um livro (Estética do objeto), está enviando uma mensagem aos seus usuários (Estética do valor) de maneira a informar o conteúdo e a narrativa que espera o leitor ao manusear o livro, considerando suas experiências e suas expectativas (Estética aplicada) para o objeto (Estética da informação), direcionando para uma estética empírica que, segundo Löback "contribui com conhecimentos aplicáveis pelo designer industrial no processo de design de acordo com as preferências do usuário" (leitor), oferecendo a eles "valores estéticos" (LOBÄCH, 2001, p.157-158). Crilly et all (2004) trata os aspectos visuais dos produtos como um fator determinante da resposta positiva do consumidor.

A estética da informação contém dados relacionados à forma, conteúdo, composição, subjetividade, características inerentes ao produto que são ampliados através do emprego da sintaxe visual. Segundo Dondis (1997) para projetar ou para compreender um projeto visual, devemos decompô-lo em elementos construtivos (forma, escala, direção, tom, cor e textura) para melhor compreender o todo, o conjunto de informações da obra. Essa questão vai de encontro à proposta de Löback (2001), ao apresentar uma interrelação entre os aspectos de construção visual e a mensagem final, percebida pelo leitor de forma integrando as questões subjetivas e objetivas.

\section{A seleção das capas}

Para realizar a análise aqui apresentada, estabelecemos um recorte na produção da década de 1960 de Vicente Di Grado. Selecionamos 05 capas que são significativas pois exemplificam a variedade de composição que explora e se relaciona com o conteúdo das obras. Essas capas são dos livros 'Pôrto do Remanso' de Geraldina Marx (1960), 'A Provinciana' de Vicente Ragognetti (1962), 'O Romance de Maria Clara' de Oliveira Ribeiro Neto (1965), 'O Segredo' de Alfred de Musset (1966) e 'O Misterioso Caso de Ritinha' de Léo Vaz (1969), conforme podemos ver abaixo (Figuras 2 a 6 ). 
Figura 2: Reprodução da capa de "Pôrto do Remanso", 1960. Fonte: Arquivo pessoal.

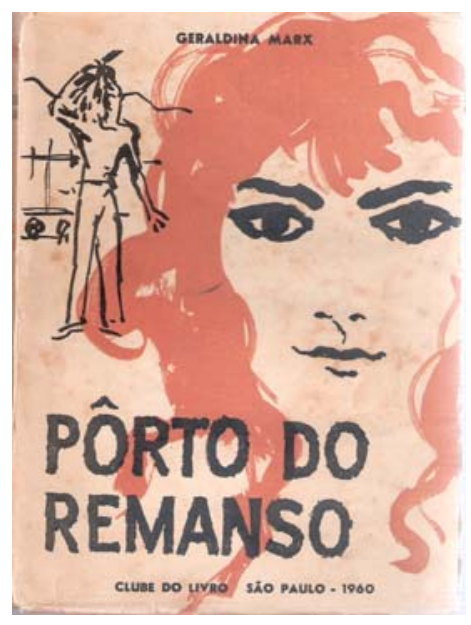

Figura 3: Reprodução da capa de "A Provinciana”, 1962. Fonte: Arquivo pessoal.

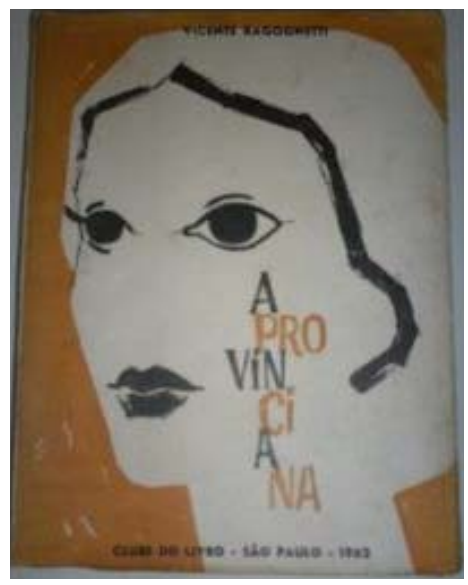

Figura 4: Reprodução da capa de "O Romance de Maria Clara", 1965. Fonte: Arquivo pessoal.

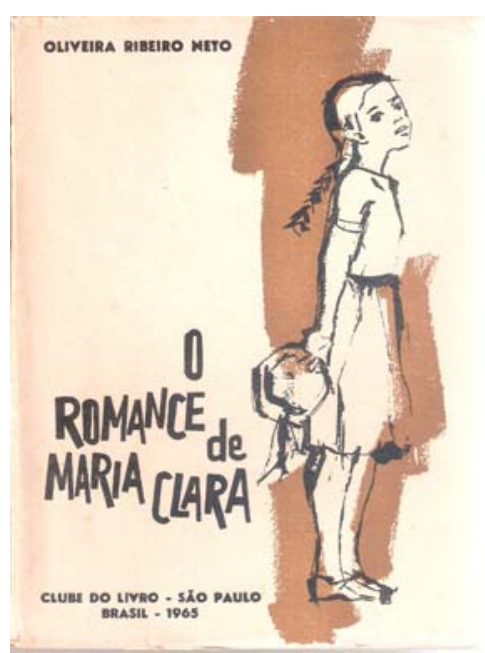


Figura 5: Reprodução da capa de "O Segredo", 1966. Fonte: Arquivo pessoal.

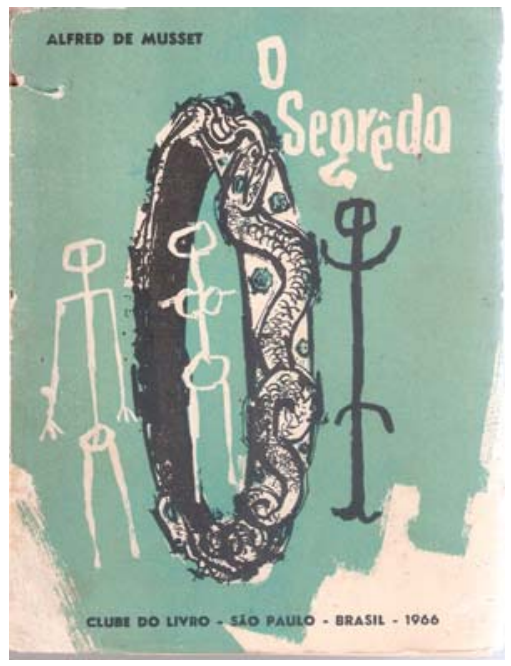

Figura 6: Reprodução da capa de "O Misterioso caso de Ritinha", 1969. Fonte: Arquivo pessoal.

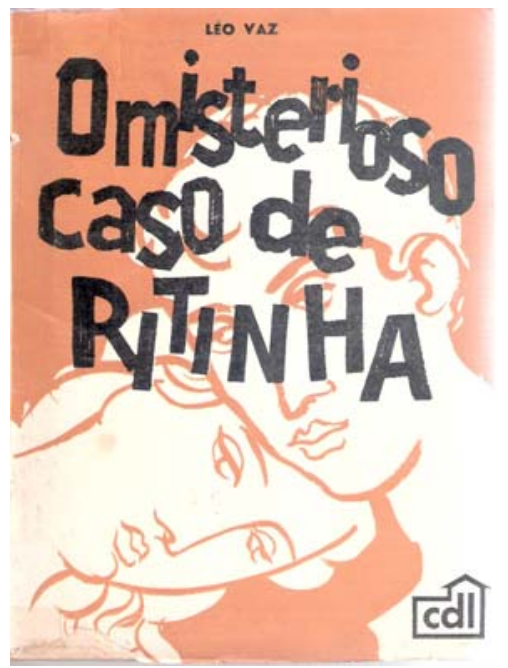

\section{Análise formal das capas selecionadas}

A análise dos elementos compositivos das capas aponta a expressividade criada por Di Grado em proporcionar aos leitores as primeiras impressões sobre o conteúdo do livro e corporificar as personagens e símbolos aos quais o título se refere e o que podemos observar a partir da ilustração. Dessa forma, atende um dos princípios de uma capa que é informar sucintamente o conteúdo a ser lido, retratando o foco da narrativa.

A composição da maioria das capas analisadas privilegia o equilíbrio assimétrico e a área direita que é organizada com pesos visuais maiores e mais determinantes, exceção se dá na capa de 'O Segredo' que estabelece uma estrutura de elementos visuais marcantes tanto a direita como na área central da capa.

A sintaxe formal das capas, nos aspectos da visualidade e textualidade, indica o trabalho de mapeamento e hierarquia das informações presentes e aplicadas nas obras que apresentam de maneira simples o nome do autor e a editora deixando como elemento central a ilustração e o título. 
No volume de "Porto do Remanso", vemos que a direção de leitura das capas de forma geral se dá verticalmente, se tratando das informações textuais (Figura 6). O que cria um equilíbrio entre texto e imagem, integrando a mancha dos olhos, à direita, com o texto colocado abaixo, à esquerda, guiando os olhos do leitor pela narrativa proposta.

Figura 6: Direção de leitura

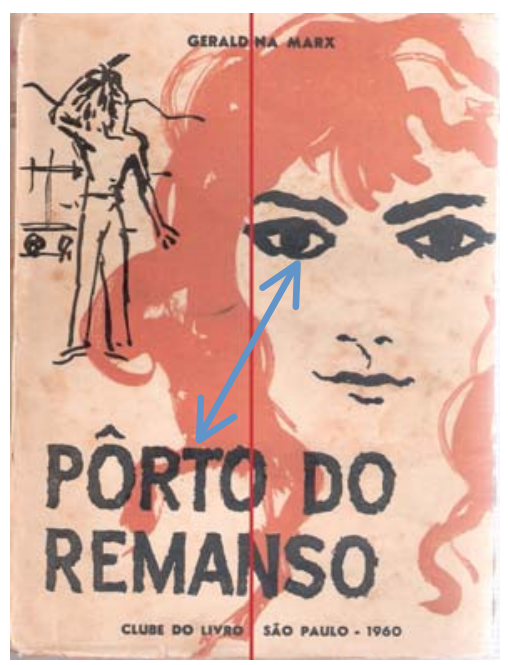

$\mathrm{Na}$ área de tensão (Centro Ótico - C.O.) localiza-se os intensos olhos da mulher que, sobrepõe os outros elementos, agindo como um fantasma a assombrar o homem, à esquerda, onde observamos uma expressão de angústia ou tristeza. A tipografia utilizada, caligráfica, 'rabiscada', desenhada pelo próprio artista, é trêmula e pesada, transmitindo a preocupação do homem. Possui uma boa leitura, mas sem perder sua característica no ritmo da leitura visual.

A ilustração é apresentada com pinceladas rápidas que traduzem o movimento do vento, característico dos portos e, os cabelos da mulher ganham volume. O primeiro plano é todo tomado pela imagem laranja que contorna os traços da ilustração.

Figura 7: Centros Ótico e Geométrico.

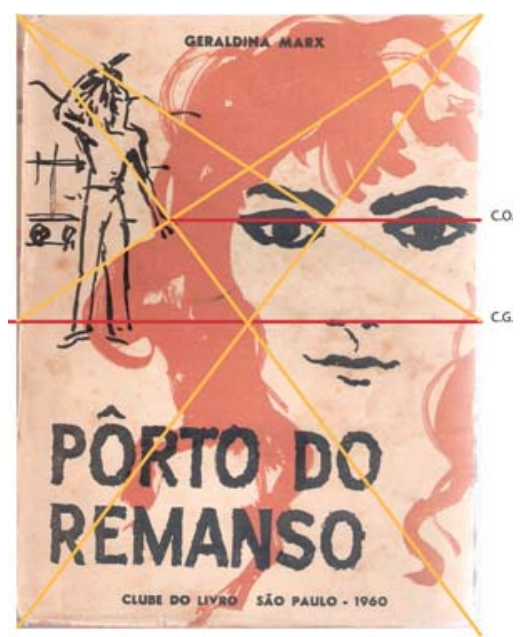

Já no título "A Provinciana", o artista cria uma composição entre título e imagem capaz de proporcionar um sentido singular. A composição visual das letras e da palavra proporcionam ao título o significado de choro, ao ser colocado logo abaixo do olho da personagem. A tipografia, desenhada com pequenas serifas, proporcionam ao texto uma leveza visual e leitura bastante sofisticada, devido a alternância entre hastes grossas e finas. 
Enquanto estrutura de organização, os olhos levemente deslocados, entre os centros ótico (C.O.) e geométrico (C.G.) (Figura 8), guiam o olhar do leitor em uma diagonal que direciona dos olhos da personagem até o título em um movimento rápido. $O$ título colocado abaixo, ao lado direito da capa, mistura a emoção da montagem com a razão que é reforçada pela face da personagem olhando para a esquerda, para traz, para o passado. A ilustração do rosto da mulher é de grande simplicidade e também de grande força visual e expressiva, uma vez que apenas um traço de grossa espessura e esse forma uma linha que divide as áreas do cabelo e do rosto. Com o mesmo partido os olhos são constituídos, grandes e intensos, assim como os lábios, carnudos e sensuais. O fundo de cor chapada, com algumas pequenas interferências de pequenos traços irregulares e interrompidos ocorrem ao redor do rosto, e, contrasta, bem como emoldura o rosto que é a figura principal.

Figura 8: Diagonal de leitura

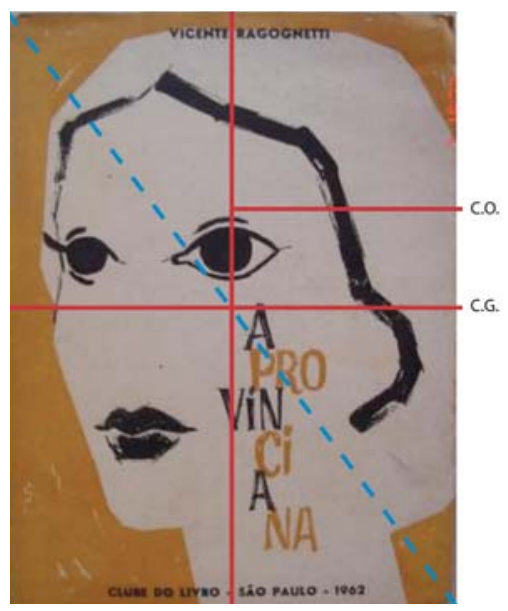

$\mathrm{Na}$ imagem da capa para "O Romance de Maria Clara", a divisão de elementos é objetiva, à esquerda as informações textuais enquanto à direita a ilustração da menina, com destaque para seu olhar disperso, localizado na zona secundária de atenção, criando a tensão necessária para deslocar o peso do texto, colocado na área esquerda inferior da capa (Figura 9).

É percebida a mancha marrom por traz da menina, o que remete ao tom da pele de seu pai, ao ler o texto introdutório, que relata a origem afro da moça e consequente tumulto social que é narrado pelo autor. A ordem visual dos elementos se contrapõe aos tipos apresentados de forma tumultuada, como a narrativa apresenta a vida da protagonista.

Figura 9: Distribuição dos elementos

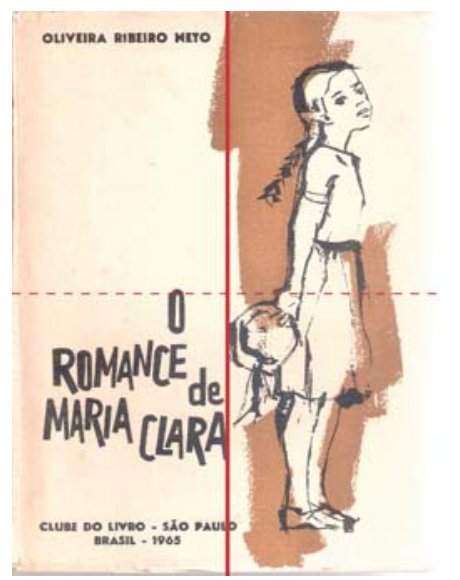

Em "O Segredo", os elementos são agrupados em torno da imagem do bracelete cravejado de turquesas (ao centro), criando um sentido vertical de leitura, sem variações, equilibrando a 
organização dos elementos de forma a criar uma informação única (Figura 10), inserindo implicitamente este objeto na trama do título. A cor verde, predominante do fundo, também faz referência a essa pedra, sendo estas os únicos elementos com cores na ilustração. As cores das ilustrações também mostram essa divisão ao existirem dois personagens brancos e outro preto.

A tipografia também é desenhada, existe uma quebra na linearidade ao baixar levemente a letra "ê", assim como o "O" inicial, desalinhando o título.

Figura 10: Sentido de leitura e agrupamento dos elementos

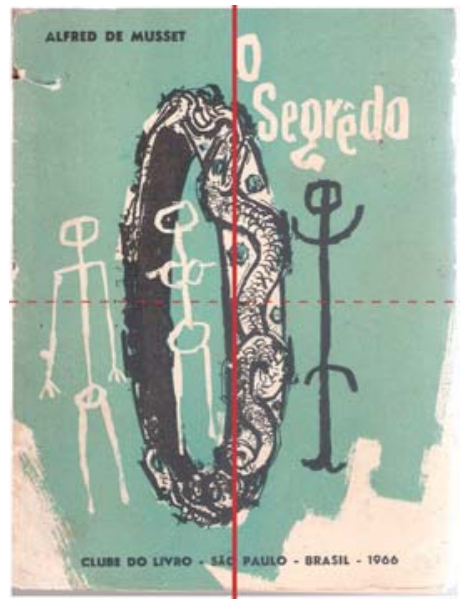

Na capa de "O Misterioso Caso de Ritinha", o título cobre parcialmente, esconde, faz o "papel de biombo' para ocultar a imagem do homem, ficando aparente somente a imagem da moça, Ritinha, personagem e protagonista do conto que intitula o livro. A leitura simples e a leveza dos traços se opõem ao peso da tipografia inserida no alto da página. A marca da editora aparece no canto inferior direito, assinando a capa com o logotipo.

Figura 11: Eixos de leitura e tensão

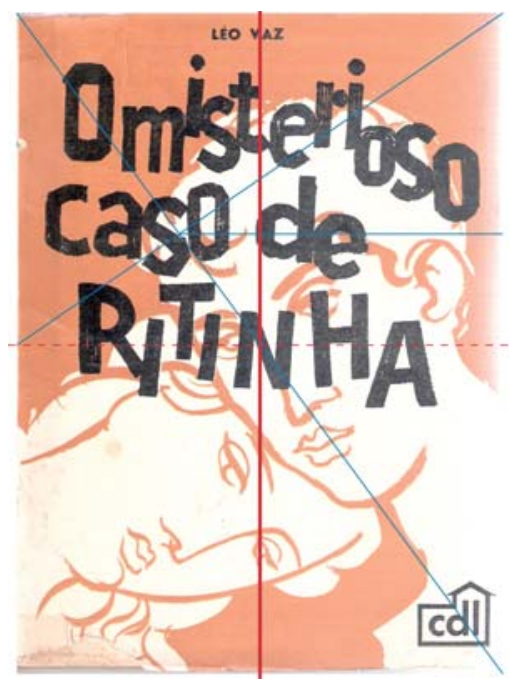

Uma das características marcantes do trabalho de Vicente Di Grado foi a relação que estabelecia entre a ilustração e a tipografia empregada, deixando a mensagem clara e objetiva, mas ao mesmo tempo, expressiva e marcante, onde é perceptível o seu domínio das linguagens pictóricas, do desenho, tanto de imagens quanto de letras e da ilustração presentes na grande quantidade de suas produções, se valendo de elementos capazes de comunicar de maneira objetiva e também subjetiva das sensações contidas na obra. 
Tanto Dondis (1997) quanto Löback (2001) e Gomes Filho (2000), se valem dos elementos de interpretação formal, para criar uma estrutura de análise gráfica, valores que para a percepção humana criam a compreensão entre o objeto (livro) e sua mensagem ao usuário (leitor).

Esta mensagem, quando vista por meio das capas de Vicente Di Grado, ganham força, provocando efeitos emocionais, reforçando o processo de estética empírica, no processo de desenvolvimento do design das capas.

\section{Considerações finais}

De uma maneira geral, as capas analisadas são marcadas pelas ilustrações e títulos em primeiro plano, dessa forma indicando a principal informação da obra. O nome do autor aparece em segundo plano, estabelecendo aí uma hierarquia de informações. Em terceiro lugar, encontramos os dados da editora, local e ano, na parte superior e inferior da capa, formando um conjunto de textos e informações complementares, variando em profundidade e peso conforme o apelo necessário ao título em questão, o design une os elementos de durabilidade e utilidade, intensificando a percepção da beleza na composição.

A pesquisa e análise das capas produzidas por Vicente Di Grado nos ajuda a resgatar a memória e a história do design brasileiro por meio do trabalho e da ação desse autor a partir de sua produção realizada na capital de São Paulo, para a Editora Clube do Livro.

Também indica a importância dos fundamentos do design da informação presentes no desenvolvimento de projetos e produtos da área do design gráfico. As capas de Vicente Di Grado indicam a síntese como resultado de um rico repertório cultural e estético e apontam possibilidades para 0 aprofundamento no conhecimento do design gráfico contemporâneo brasileiro.

\section{Agradecimento}

Ao Sr. Aroldo e filho, proprietários dos Chaveiro Dia a Dia \& Sebo e Sebo Salva Pátria, em Marília, SP, por disponibilizar seu acervo para a realização da pesquisa.

\section{Referências}

CARDOSO, Rafael (Org.). 2005. O design brasileiro antes do design: aspectos da história gráfica 1870-1960. São Paulo: Cosac Naify.

CRILLY, Nathan; MOULTRIE, James; CLARKSON, P. John. 2004. Seeing things: consumer response to the visual domain in product design. In: Design Studies. v. 25, n. 6, November 2004, p. 547-577. Disponível em $<$ http://www.sciencedirect.com/science/article/pii/S0142694X04000225 >. Acessado em 27/04/2012.

DONDIS, Donis A. 1997. Sintaxe da linguagem visual. São Paulo: Martins Fontes.

DÜRSTELER, Juan C. 2000. Diseño de Información: no confunda al recién llegado. Revista InfoVis.net. n. 9. Publicado em 18/09/2000. Disponível em $<$ http://www.infovis.net/printMag.php?num=9\&lang=1>. Acessado em 26/04/2012.

FERLAUTO, Claudio. 2002. O Tipo da Gráfica uma continuação. São Paulo: Edições Rosari.

GOMES FILHO, João 2000. Gestalt do objeto: Sistema de leitura visual da forma. São Paulo: Escrituras (2.ed.)

HALLEWELL, Laurence. 1985. O livro no Brasil - sua história. São Paulo: T.A. Queiroz / EDUSP.

LÖBACH, B. 2001. Design Industrial: bases para a configuração dos produtos industriais. São Paulo. Edgard Blücher.

MELO, Francisco Homem (Org.). 2007. O design gráfico brasileiro: anos 60. São Paulo: Cosac Naify.

PETTERSSON, R. 2002. Information design: an introduction. Amsterdam: John Benjamins Publishing Co. 


\section{Sobre os autores}

Márcio Duarte, mestrando no PPG Design UNESP com pesquisa sobre Vicente Di Grado e o design editorial no segmento de livros, é especialista em marketing e bacharel em publicidade e propaganda. É membro do Grupo de Pesquisa em Design Gráfico Contemporâneo. Atualmente é docente na Faculdade do Interior Paulista (FAIP) no curso de Moda e Estilismo e do Centro Paula Souza no curso de Informática para Internet, onde também é Coordenador de Área.

marcio@marcioduarte.com

Mônica Moura, Doutora em Comunicação e Semiótica pela Pontifícia Universidade Católica de São Paulo na área de concentração Signo e Significado nas Mídias. Atualmente é Professora Assistente Doutora do Departamento de Design e Professora Credenciada do Programa de PósGraduação em Design da UNESP, Faculdade de Arquitetura, Artes e Comunicação (FAAC), Campus de Bauru. Atua nas linhas de pesquisa em Planejamento de Produto; Teoria e Crítica de Design. Coordena o Grupo de Pesquisa em Design Gráfico Contemporâneo. É Presidente da Sociedade Brasileira de Design da Informação - SBDI e membro fundador e da diretoria da Associação Brasileira de Estudos e Pesquisas em Moda - ABEPEM. É responsável pela Editoria de Design da Editora Estação das Letras e Cores e Colunista da Revista Dobras. Tem várias publicações na área de Design, atuando com os seguintes temas: Teoria do Design; Ensino em Design (Interdisciplinaridade e Transdisciplinaridade); Design Gráfico; Design de Moda; Relações Design, Arte e Artesanato; Design da Informação; Mídias Digitais; Design Contemporâneo.

monicamoura.design@gmail.com 